\title{
Science in the digital age
}

The goals of science have not changed since the early days of the Lindau meeting, yet the way they are pursued has.

\section{BY NED STAFFORD}

1 The year was 1947—no high-powered personal computers and no internet for seemingly magical keyword searches of massive databanks. So when Oliver Smithies, a 22-year-old science student at Oxford University, was assigned an essay on the Pauli exclusion principle, he did what students and scientists in search of knowledge had been doing for centuries.

He went to the library to sift through scientific journals and books. His keyword search for pertinent information consisted of scanning page after page with his eyes. When Smithies, who 60 years later won the 2007 Nobel Prize in Physiology or Medicine, finally finished researching his essay, he had the pleasure of writing it by hand.

"I think the biggest single change between then and now is the huge amount of information that is available," says Smithies, born in the UK but now a US citizen, still involved in medical research at the University of North Carolina at Chapel Hill.

Indeed, the digital revolution has transformed the creation, storage and transfer of knowledge (see Xue-fu-wu-che). The ultimate goals of science remain unaltered in this new world, but the paths that scientists traverse to reach them have changed, triggering a further cascade of new developments.

"This could not have been imagined twenty years ago," says Liu Dun, a science historian at the Institute for the History of Natural Science, Chinese Academy of Sciences, in Beijing. "With just an internet terminal, scientists today are able to access almost all important resources of literature in different languages and from different ages, countries and fields."

Scientists now are able to bypass traditional publication routes by quickly and easily

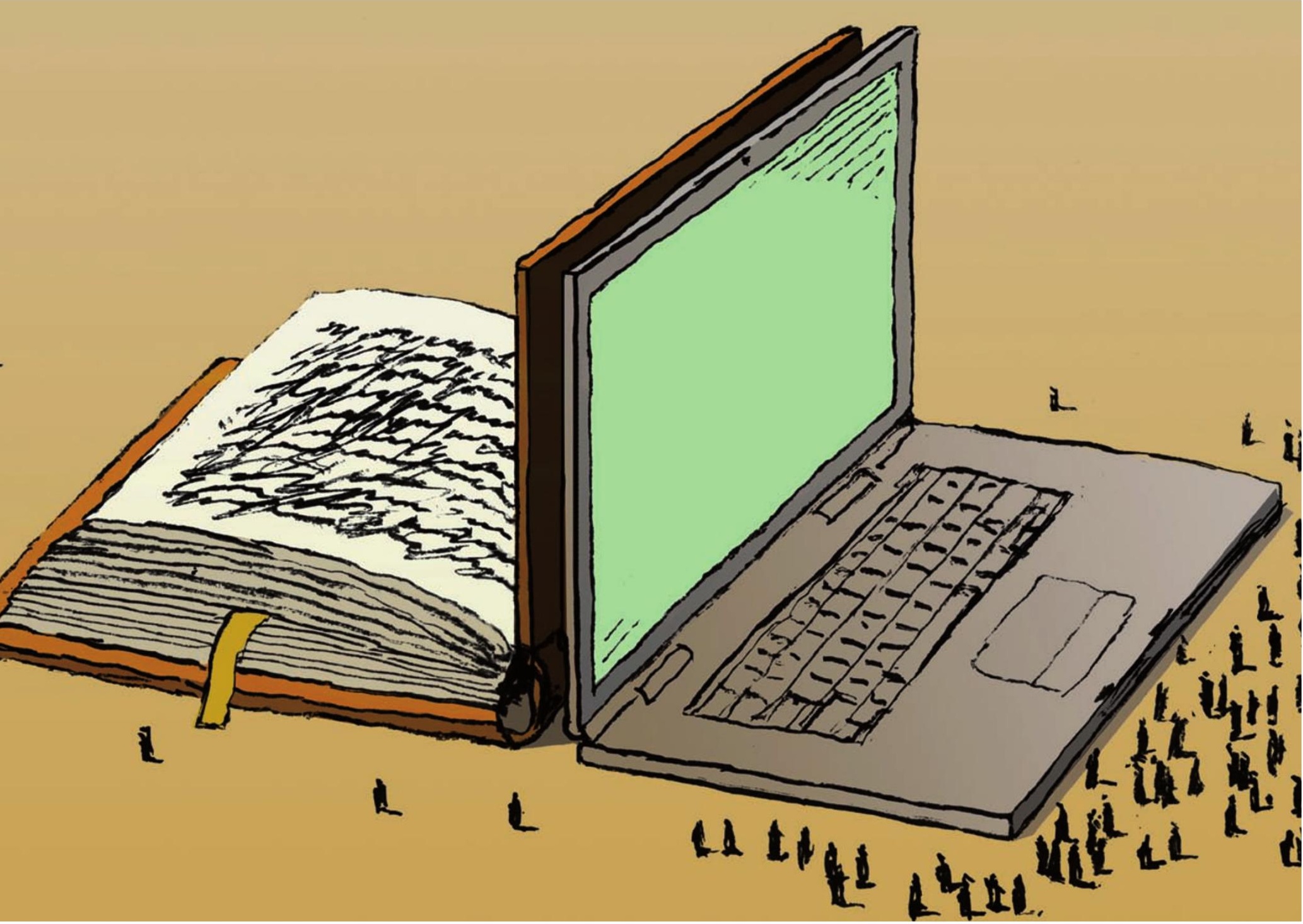


posting academic papers, scientific data and personal blogs on the internet. Cheats have never had it so easy, able to copy and paste others' electronic information with little more than a mouse-click and claim it as their own. There is an ever-expanding array of high-tech — and often high-cost - laboratory tools for pursuing research. It is commonplace to have to jostle not only for smaller slices of the funding pie, but also for tenured academic positions. And scientists are now expected to be constantly available to colleagues around the world via email, mobile phones, Twitter, or other fashionable means.

As Liu Dun, who is also president of the Division of History of Science and Technology, part of the International Union of History and Philosophy of Science, notes, this new digitally influenced world of science has rapidly evolved in less than a generation. The current crop of university students and young researchers know only a world of science that, to most of their current professors and lab leaders, would have seemed like science fiction 20 years ago.

\section{PAPER EQUALITY}

Publish or perish, remains a maxim for today's youngest generation of scientists as it did for previous generations. Scientists around the world are still eager - for professional ambition and personal pride - to have their papers published. As Smithies says, "It isn't science until it is published."

Until recent years, there was one primary route to publication: submission to peerreviewed journals. Usually several months to a year later the paper would be published in the journal, and then posted to personal subscribers and libraries, allowing other scientists to finally read it.

But not all scientists in the traditional publishing system were created equal. David Kaiser, a physicist and faculty member of MIT's Program in Science, Technology, and Society, says that from around the 1930s until recent times, some scientists tried to speed up the process by sharing pre-prints of their papers, but these were usually restricted to a select group of insiders. "In order to get the inside scoop on an upcoming paper, to see a preprint, you had to be on the A-list of top scientists, something like the old-boy network," says Kaiser. "That is quite different today. Publishing is much more open now, and new resources like the internet allow scientists to bypass the previous exclusivity."

For a successful example of open-access publishing, Kaiser points to the arXiv database administered by Cornell University in New York. "You can post papers on arXiv immediately," he says, adding that this includes posting papers before they are peer-reviewed.

The obvious benefit of open-access online publishing is to increase the speed of sharing ideas with other interested scientists. Kaiser sees potential benefits in circulating ideas

\section{XUE-FU-WU-CHE}

In ancient China, before the invention of paper, books were made of wood or bamboo scrolls - cumbersome, especially for wandering scholars of the time. Back then, says Liu Dun of the Chinese Academy of Sciences, a learned man was called xue-fu-wu-che - literally 'a possessor of five cartloads of knowledge'. He adds, "By today's standard, however, books on bamboo scrolls filling five cartloads may be contained in a memory chip less than one gigabyte."

before they have gone through rigorous peerreview. The peer review system, in his view, is clearly important and a valuable step in the formulation and communication of ideas, but it can sometimes weaken the impact of original, ground-breaking ideas. "A raw idea can really be much more inspiring than the cleaned up peer-reviewed idea presented a year later," he says.

Downsides to the glut of material being publishing online are that this material might be low quality and scientists risk drowning in the continuous gush of data, Kaiser says, add-

"A raw idea can really be much more inspiring than the cleaned up peer-reviewed idea presented a year later." ing: "You sort of get a feeling that you are running a marathon that never ends. I think one can make a very strong case we are all suffering from that."

Jane Maienschein, director of the Center for Biology and Society at Arizona State University, says: "It's easy to get access to abstracts and public information, but much harder to actually read the whole thing. I know scientists who read the open access abstracts and assume they know enough."

Cameron Neylon, a biochemist and senior scientist at the Science and Technology Facilities Council, a funding agency in the UK, agrees that scientists are being buried under millions of gigabytes of information, some of dubious quality. But Neylon believes the boon to science from this deluge of information far outweigh the disadvantages.

"Look at all the general information on the web," he says. "But the web still works because you can go to Google or other search engines to filter information to find what you are looking for. We need to do that for science."

Neylon wants to go beyond open access publication of academic papers. He advocates a concept dubbed 'Open Notebook Science', in which scientists post the full primary record of research projects - their laboratory notebooks - on the internet for public scrutiny. "The core of the concept is simple," he says. "You keep your primary research record openly available on the web." (See Open notebook science).

\section{OPEN TO TEMPTATION}

New communication technologies bring opportunity, but they also come with drawbacks. The exchange of ideas, feedback, advice, critique and encouragement among scientists has always been key to moving science forward. Until a couple of decades ago, longdistance personal communication between scientists was essentially limited to letter writing and land-line telephones. These have been supplanted by the instantaneous mediums of email, mobile telephones and the internet.

There can be no doubt that the ease of email is helping to progress science. As Smithies notes, it "improves the transmission of knowledge so improves science". But, he opines: "I personally don't care much for emails. I prefer talking. I find I have to email a person to get them to pick up the phone."

Modern technologies cannot replace personal contact. "People are connected through quick-fix email," says Maienschein. "But this does not lend itself to thoughtful or deeply reflective exchanges. This is why we still need in-person conferences. Even video chats don't do the whole job with larger groups of people."

There are more nefarious consequences of these new technologies too. Although plagiarism is nearly as old as publishing itself, the difference is that unethical students and scientists now have handy tools for finding information and claiming it as their own. However these same tools can be turned against the cheats, according to Harold Skip Garner, head of the Virginia Bioinformatics Institute at Virginia Tech, who helped develop eTBLAST, the institute's free web-based search engine that can be used to catch plagiarists.

"In the recent past, that is only two to three years ago, most plagiarism discoveries were serendipitous," says Garner, who has studied plagiarism by searching millions of online papers to reveal that thousands have large similarities with other articles. "But now they are being discovered en masse using computer techniques."

A simple keyword search, such as "plagiarism checkers", on the internet will yield a long list of text-based search systems, some free and some as commercial products. Garner says that most currently available software is limited to checking newly submitted manuscripts for possible plagiarized content. However, some can scan several databases, such as Medline, CRISP (from the National Institutes of Health) and IOPscience (from the Institute of Physics), and identify highly similar articles already in print.

"It will soon become impossible to evade detection as more and more publications are available electronically," Garner predicts. And he warns that past cheats not yet caught should be concerned: "Those who cheat or 


\section{OPEN NOTEBOOK SCIENCE}

A small but growing number of scientists practice Open-Notebook Science (ONS), a concept whereby researchers post their laboratory notebooks on the internet for public scrutiny. The term was coined in 2006 by Jean-Claude Bradley, a chemist at Drexel University in Philadelphia, who now defines ONS as "the practice of making the entirety of one's laboratory notebook and all associated raw data public in as close to real time as possible". He adds that this should include information not usually disclosed, such as results from failed or ambiguous experiments. "For the open researcher, the greatest benefits are probably enhanced visibility and the ease of identifying new collaborators."

Open-notebook advocate Cameron Neylon says that the most important benefit would be to move science forward at a quicker pace. "The more people you have looking at a problem the better chance you have of solving it," he contends. Input from outsiders could also help reduce lab expenses. "Science is expensive and specialized," he says. "It is going to be rarer and rarer to have all the expertise needed inside your own laboratory or within your team."
There is a wide range of access options for publishing notebooks on the web, from password protection, creating different access options for different types of user, to "opening it up to the whole world", says Neylon. Software developers are working to make open notebooks easier for scientists to use and, at some point, fully automated so that data are transferred to the internet in real time.

Notebook information is time-stamped to record and attribute a new idea or result. "There will be cases of theft, but they will be easy to spot," says Neylon. "People are always going to try and play the system. But this kind of cheating becomes much harder in a transparent environment."

Ultimately, Neylon believes open-notebook users, both posters and readers, will end up in a stronger position by working together. "Funders of research projects do not really care whose names end up on papers, they just want to get [the projects] done," says Neylon. Funders should be among the biggest supporters of ONS and encourage its wider use, he adds. "I do sometimes wonder why funders don't just lose their patience and tell us to quit mucking about." have cheated even long ago must realize that the evidence for their actions is permanently out there, so there is the lingering possibility of being found out."

\section{FLASHY SCIENCE}

Laboratories today also are undergoing major changes, with even the simplest labs outfitted with expensive equipment. Smithies recalls that early in his scientific career at Oxford University in the UK, the most modern tool in his lab was an ultracentrifuge, at that time a huge oil-powered contraption that occupied two rooms. The latest models, in comparison, are compact desktop units. Back then, he says, "a lot of experiments could be done with relatively simple equipment." How does this affect the science? "High-tech lab equipment makes

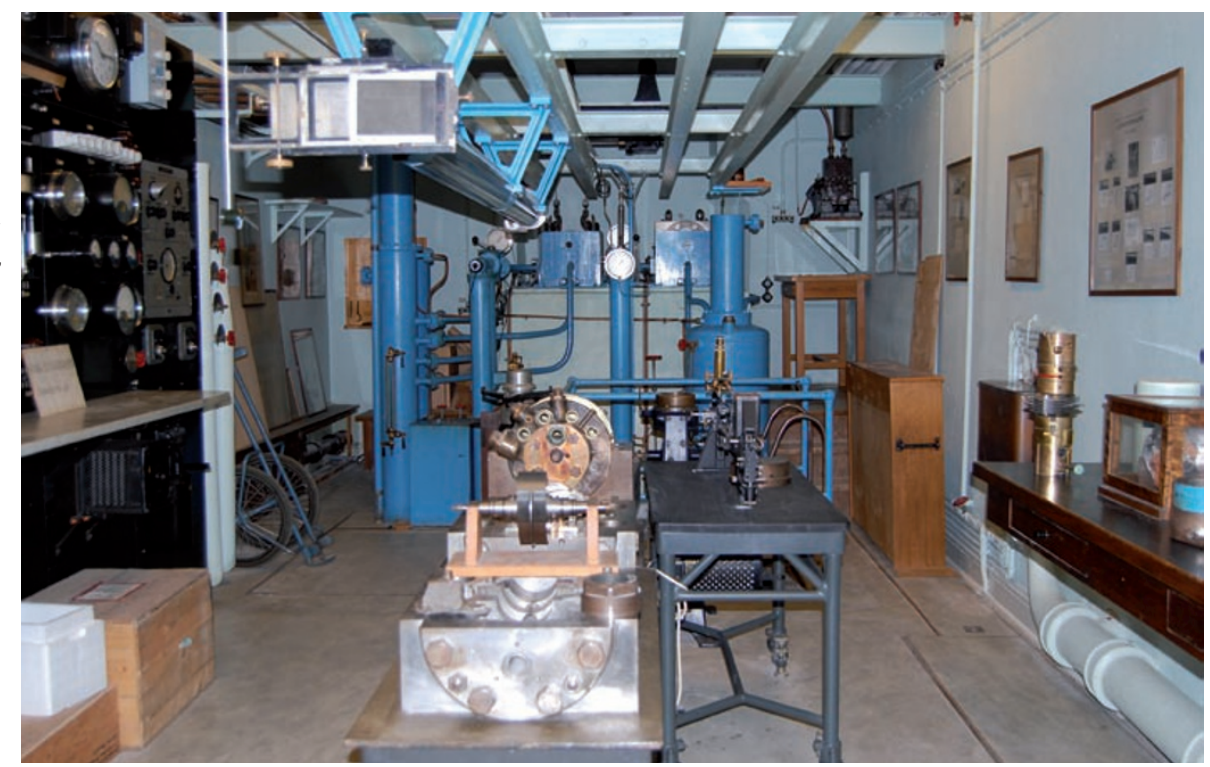

Original ultracentrifuge equipment at the Svedberg laboratory, Uppsala University. The optical detectors (foreground), black electric switchboard (left) and the blue turbines and oil-pumps (background) are only part of the instrument - the rest is in the room below.

it easier to get more information, but does not necessarily improve science unless you do something with it. Science is what you do with the information," he says.

What it has done is infuse science with a sense of 'keeping up with the Joneses'. Maienschein observes that "there is great pressure to use the latest and greatest equipment, which may not actually be necessary for some questions and approaches. This may distort some of the science that gets - or doesn't get - done".

Outfitting modern labs with expensive tools requires significant portions of scarce resources, yet little thought is given to the rapidly growing mountains of scientific information. "Government grants don't include support for the infrastructure to collect, archive, and then use combinations of data,"

archive, and then use combinations of data," to 